\title{
ON SOME RECENT REMARKS ON THE PHYLOGENY OF HOMOPTERA.
}

\author{
By F. MuIr, \\ Hawaiian Sugar Planters' Experiment Station, \\ Honolulu, T. H.
}

In a recent publication Dr. G. C. Crampton ${ }^{1}$ remarks: "In any phylogenetic study we must consider the lowest representatives rather than the highly specialized members of a group."

Unfortunately Dr. Crampton, on more than one occasion whell discussing the phylogeny of Homoptera, has not followed this good advice. In a recent paper ${ }^{2}$ he has compared the wing of a Psyllid and a wing of a Psocid and concluded that their similarity is due to their common ancestry. The Psocid wing he figures is a specialized one and not the lowest representative of the group, and Psyllidæ are highly specialized Homoptera. Any similarity between the venation of the wings of these two insects is therefore of no phylogenetic significance, but due to convergence.

As I am not an authority upon the Psocidæ I can only support my contention by a comparison of the Psocid wing figured by Dr. Crampton with such genera as Amphientomum and Cymatopsocus, where the venation is more generalized but still too specialized to he ancestral to the Homoptera.

My contention that the Psyllidæ do not represent the primitive type of Homoptera is based upon a detailed study of the suborder. The evidence is too lengthy to give in detail in this paper, but the following is a brief summary of some of the points.

The Hemiptera form a homogeneous and monophyletic order characterized by a unique shape and arrangement of the mouth parts found in no other order of insects. Although the order is of great size and the forms found within it are very diverse, yet the mouthparts are always of the same type and far more uniform than is found in any other of the large orders. That such a typo of mouth organs should have arisen independently in two or more groups seems highly improbable.

The nearest approach to the Hemipterous mouthparts is found

1 Proc. Ent. Soc. Washington 23, 2, p. 37 (1921).

2 Ent. News XXII, No. 4, p. 97-105 (1921). 
in the Thysanoptera. But here we find two distinct types of mouth organs and both are so dissimilar to the Hemiptera that it is not likely that one arose from the other. The Psocidæ possess a. semi-free maxillary style which may represent a condition found in the ancestors of the Hemiptera, but no Psocids that we know today could have been that ancestor because they are far too specialized in certain directions.

The most generalized head in the Hemiptera is found among the Heteroptera where the gula is well developed or very large, the head capsule of more normal shape and position, the labium is four-jointed and consists of a snbmentum, mentum, subgalea with amalgamated paraglossa and lacinia. In some few species the labial palpi are also present. In the Homoptera the gula has disappeared or is represented only by a membrane, and the labium is in close association with the pronotum. The reduction of the gula has drawn the head downward and under, bringing the top of the head to the front and altering the whole shape of the heai capsule. In this respect the Cicadoidea are more primitive than the Fulgoroidea.

In the Sternorhynchi this line of evolution of head set up in the Auchenorhynchi is carried to a still greater extent. In the Psyllidæ the clypeus, frons (bearing the phrayngeal muscles), tentorial structure and the labium have separated themselves from the head capsule and become still more closely connected with prosternum. To accommodate the long mandibular and maxillary setæ an invagination at the base of the labium penetrates the prothorax. In the Coccidæ the reduction of the head capsule is carried to the extreme, so that the frons, clypeus, tentorial structure, labium and the styles are isolated in a membraneous area and appear to be thoracic structures. The line of evolution of the head of the Hemiptera is so well defined that any student of comparative morphology, except an extreme mutationist, will agree that the Psyllidæ are highly specialized and do not represent the ancestral form.

The Hemiptera can be divided into two groups on the condition of the alimentary canal. In the Heteroptera, Fulgoroidea and Cicadellidæ this is simple. In the Cicadadæ, Cercopidæ, Membracidæ and the Sternorhynchi the posterior portion of the midgut is in intimate contact with the anterior portion and forms a filter 
chamber. This is of a simple nature in the Psyllidæ. The fact that this division separates the Cicadellidæ and the Membracidæ raises difficulties, as they are otherwise so closely related. It seems improbable that such a condition arose in two or more groups independently. It seems more probable that it has been lost in two or more groups independently. Kershaw has shown that the connection is fully developed in nymphs when hatched, so that it is an embryonic character and not a later development to meet special conditions.

Judging by venation the Hemiptera must have divided into two groups, the Homoptera and Heteroptera, early in the history of the order, but not early enough, in my opinion, to justify making it into two orders. A very slight study of the venation of the Homoptera shows that the nearest approach to the hypothetical ancestral type is not found among the Psyllidæ but among the Auchenorhynchi.

A study of the hind legs also indicate a state of high specialization in the Psyllidæ.

Again, in discussing the male genitalia of Homoptera, Dr. Crampton has offended against his own advice. Although there are several distinct types of both male and female genitalia among the Auchenorhynchi he has selected Ormenis as the type to homologize with other orders. But unless it can be shown that this genus possesses a generalized type, any homologies drawn from it are of little phylogenetic value.

Among the Cicadoidea we have two distinct types of male genitalia and a third in the Fulgoroidea. Cicadadæ have no genital styles or these are only rudimentary and are articulated and the aedeagus comparatively simple. This is most likely specialization by reduction. In the other Cicadoidea there are two pairs of appendages, the outer pair or plates and the inner pair. In some forms the outer pair are amalgamated together and appear to be part of the pygofer. In the Membracidæ the aedeagus is generally simple; in the Cercopidæ it is often complex; in the Cicadellidæ it is of various forms, some of which are highly compler and others greatly reduced. In the Fulgoroidea there is only ons pair of styles, which in certain cases are amalgamated into a single organ.

Both the inner styles of the Cicadoidea and the styles of the 
Fulgoroidea are in connection with the base of the ædeagus. They are probably homologous.

In the Fulgoroidea there is great diversity of structure and it is very difficult to decide which is the most generalized. In certain forms (i. e., certain Delphacidæ) it is of a simple tubular nature with a small ring round its base. In other forms this ring is greatly enlarged and forms an outer tube around the inner tube. In some forms there are even three tubes and one may be exceedingly complex.

Until we understand the homologies of the various types within the order Hemiptera any homologizing with other orders is but guesswork and not scientific evidence, although the guesses may be correct.

Dr. Crampton has so often associated the Psocidæ and Psyllidæ together, as if the latter were descended from the former and all else followed naturally, that there is a possibility of readers not acquainted with the Homoptera accepting that conclusion as well founded. For that reason I raise the above objections.

Certain remarks in Dr. Crampton's papers leads one to believe that he holds views on evolution considerably different to those of the majority of biologists; or his metaphors are so anthropomorphic that they are misleading. As an example of this I quote from a recent work $\mathbf{~}^{3}$

"Taking their anatomy as a whole, the Hymenoptera show undoubted affinities with the Neuropteroid insects (i. e., the Neuroptera, Mecoptera, Tricoptera, etc.), but they also present certain points of similarity to the Psocoid insects, such as the Homoptera, Thysanoptera, Psocida, etc. The lines of development of all of these forms apparently arose from ancestors intermediate between the Zoraptera (with the Isoptera) on the one side, and the Coleoptera (with the Dermaptera) on the other-much as a family of children inherit traits from the father's side-and I am inclined to consider that the Hymenoptera inherited their social tendencies from the side of the Zoraptera (with the Isoptera) while their type of genitalia apparently comes from the side of the Coleoptera (with the Dermaptera)."

Does Dr. Crampton believe that new orders arise as hybrids from the crossing of individuals belonging to different orders, or are things not what they seem in the quoted paragraph?

Ent. News XXXII 5, (1921) p. 137. 

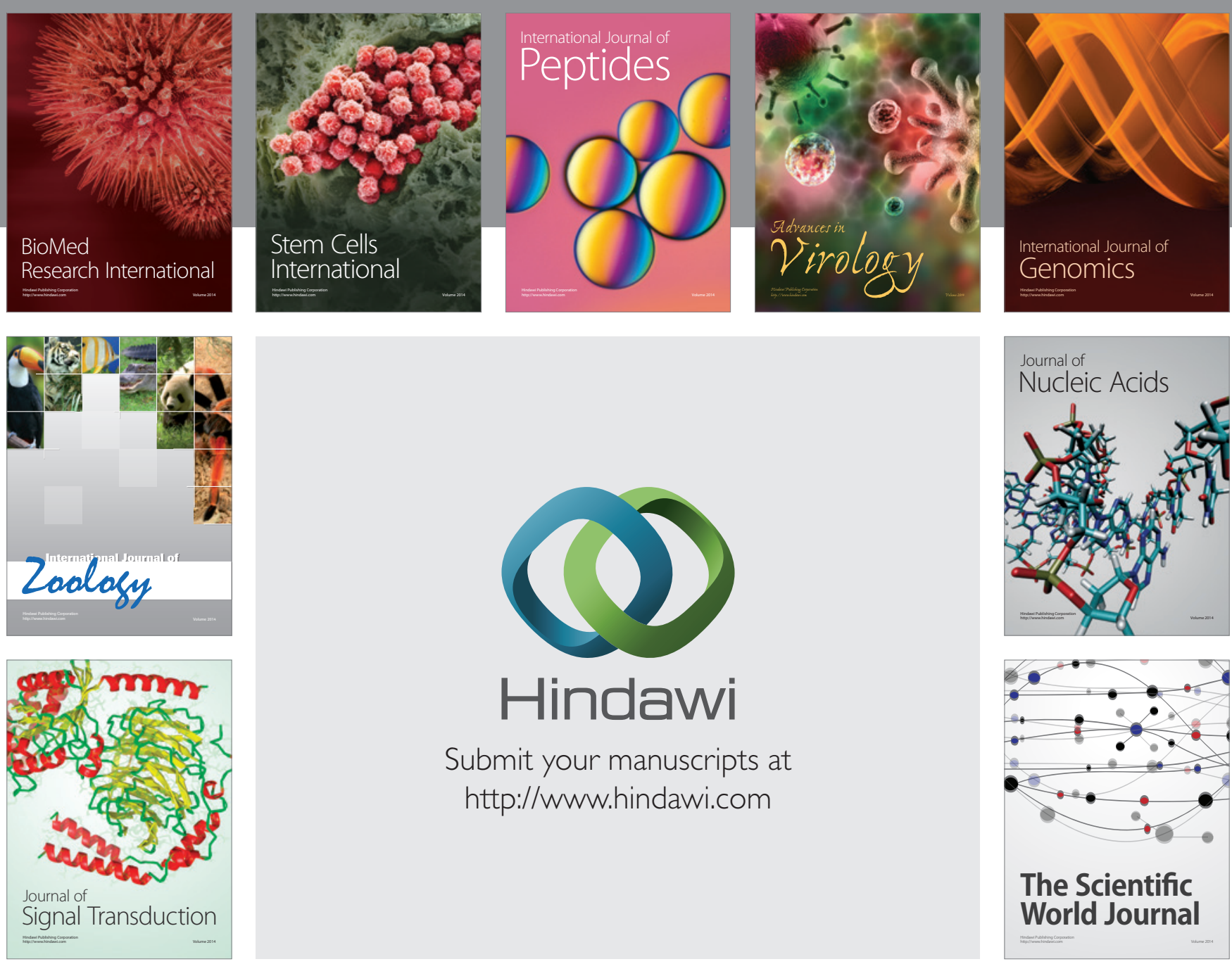

Submit your manuscripts at

http://www.hindawi.com
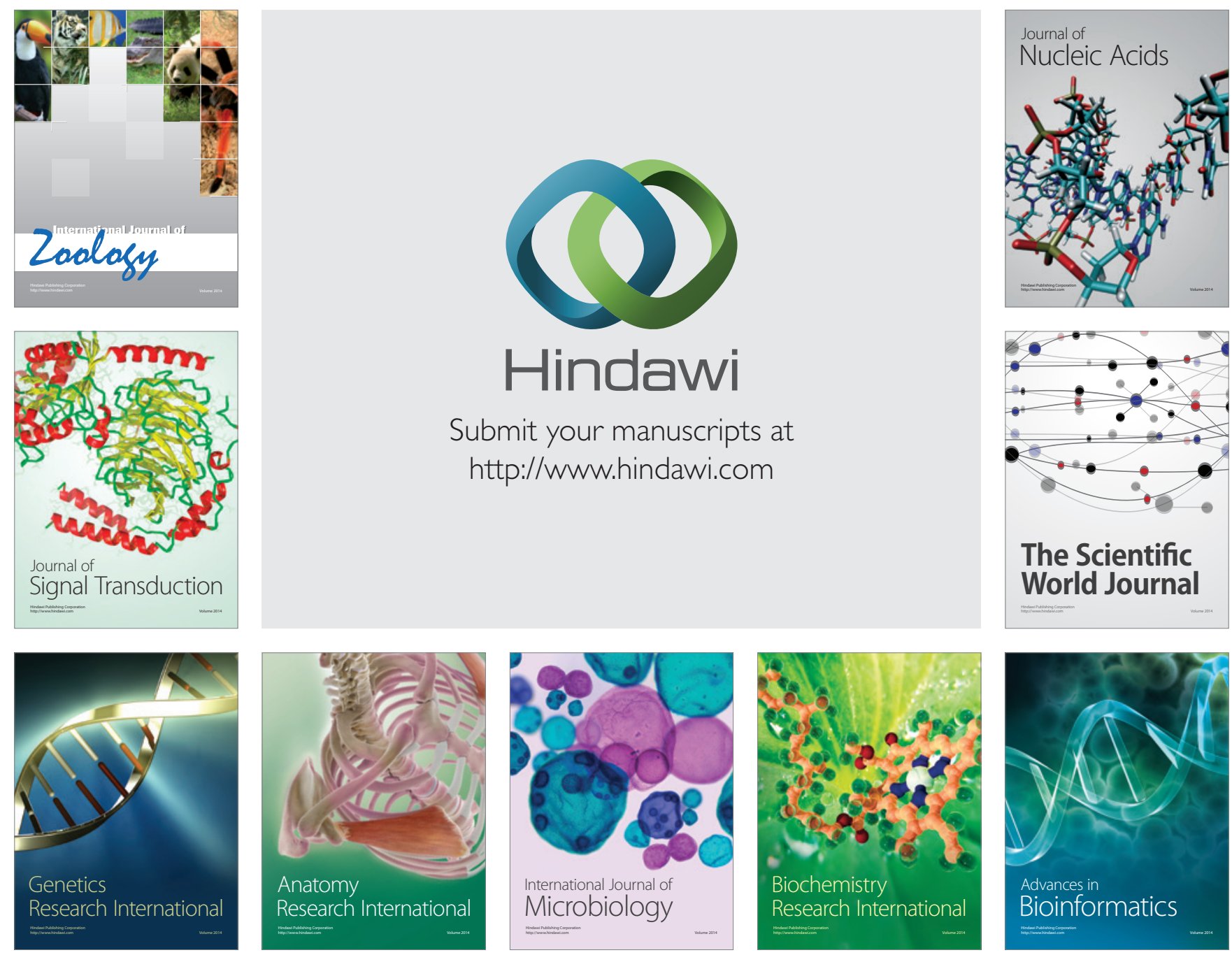

The Scientific World Journal
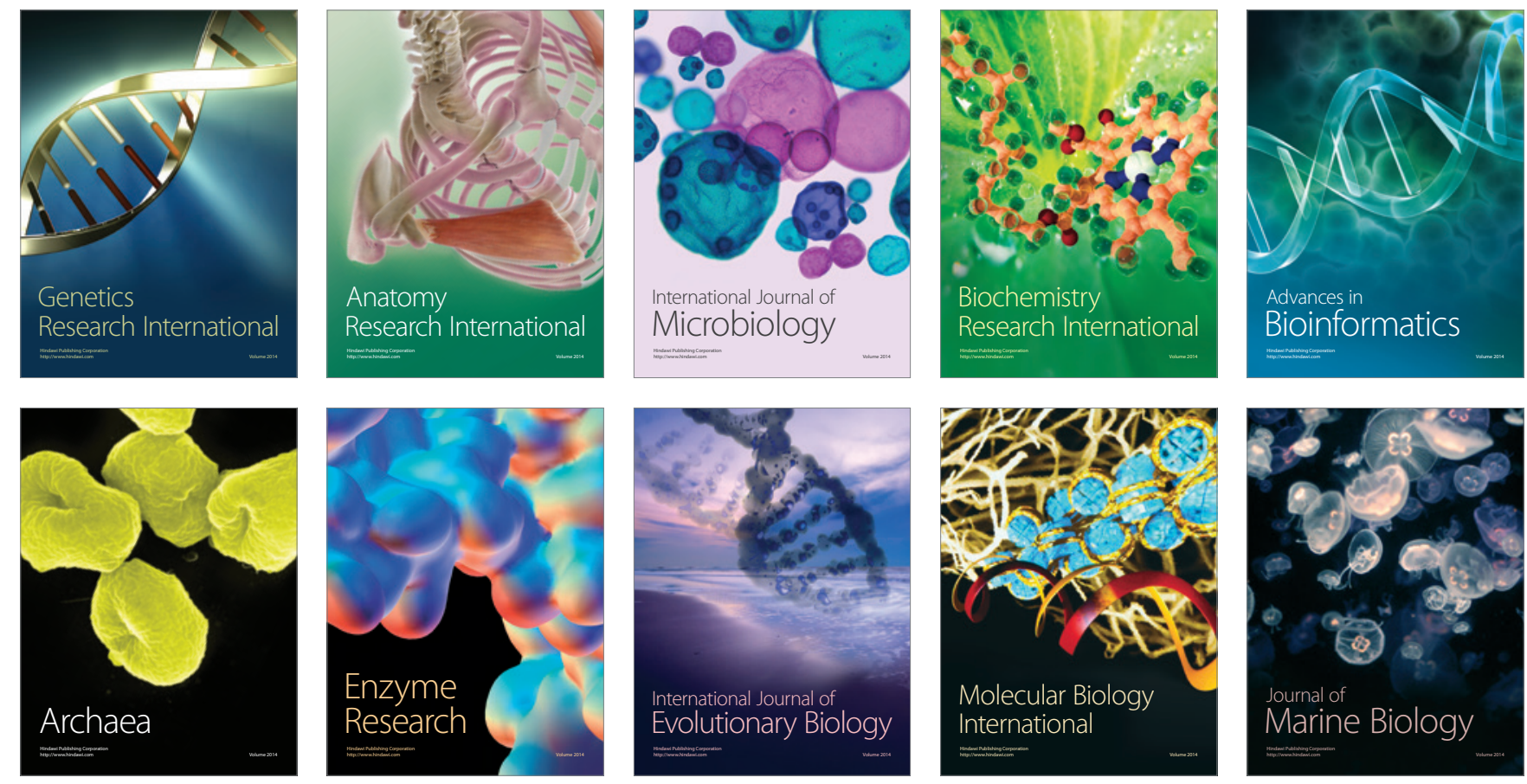